Thaís Gomes V. Silveira 2 U esl ei Teodoro 2

Maria Valdrinez C. Lonardoni 2

Max Jean Ornelas de Toledo 2

Dennis Armando Bertol ini 2

Sandra Mara A. A. Arraes 2

Dirceu Vedovello Filho 3

\section{Investigação sorológica em cães de área endêmica de leishmaniose tegumentar, no Estado do Paraná, Sul do Brasil 1}

\author{
Serologic survey of dogs in an endemic area of \\ tegumentary leishmaniasis in Paraná State, \\ southern Brazil 1
}

\footnotetext{
1 Pesquisa financiada pela Fundação Nacional de Saúde e Secretaria de Estado da Saúde do Paraná.

2 Departamento de Análises Clínicas, Universidade Estadual de Maringá Av. Colombo 5790, Maringá, $\mathrm{PR}$ 87020-900, Brasil.

3 15a Regional de Saúde de Maringá,

Rua Demétrio Ribeiro 50 Maringá, $P R$ 87020-900, Brasil.
}

Resumo A crescentenotificação de leishmani ose tegumentar no Estado do Paraná requer a busca de expli cações para o esclarecimento da epidemiologia desta doença e dos mei os para o seu controle. Realizou-se um inquérito sorológi co para investigar lei shmaniose tegumentar em cães de seis propri edades agrícol as da Companhia Mel horamentos Norte do Paraná, situadas nos municípi os de Jussara e Terra Boa, no Noroeste do Estado do Paraná. Foram investigados 132 cães, dos quais 24 (18,2\%) apresentaram títulos si gnificati vos de anti corpos através da técnica de Imunofluorescência Indi reta (IFI). De seis cães apresentando lesões foram fei tas lâminas de esfregaço por aposição, as quais foram negativas para Lei shmania sp. à microscopia direta.

Palavras-chave Leishmaniose; Leishmania sp.; Lei shmaniose Canina; Epidemiologia; Zoonose

Abstract Increased reporting of mucocutaneous leishmaniasis in the State of Paraná points to the need for information on both this disease's epidemiology and pertinent control measures. A serological survey was thus performed, with indirect immunofluorescence (IIF) for canineleishmaniasis in farm operations bel onging to the Companhia Melhoramentos Norte do Paraná, in Jussara and Terra Boa counties, in northwestern Paraná. IIF was performed on 132 dogs, of which 24 (18.2\%) had significant titers $(\geq 40)$. Imprints of six dogs with lesions were made and all were negative for Leishmania sp.

Key words Leishmaniasis; Leishmania sp.; Canine Leishmaniasis; Epidemiology; Zoonosis 
Introdução

A leishmaniose tegumentar (LT) é uma doença endêmica no Brasil (Coutinho et al., 1981; Guimarães et al., 1983; Grimaldi et al., 1989), com número crescente de casos notificados (Vieira et al., 1990; FNS, 1993), em áreas que sofreram grandes alterações antrópicas (Dias et al., 1977; Barreto et al., 1984; Barros et al., 1985). No Noroeste do Estado do Paraná a doença tem perfil endêmico (Verzignassi et al., 1988; Teodoro et al., 1991; Silveira et al., 1992, 1994), mas nos últimos três anos a notificação de casos aumentou significativamente (comunicação pessoal de E. A. Fukui, Diretora da 15a Regional de Saúde eJ. F. Konolsaisen, Centro de Epidemiologia, Secretaria de Estado da Saúde do Paraná).

A participação de animais domésticos no ciclo epidemiológico da LT nas Américas é conhecida desde o início deste século (Falqueto et al., 1986). No Brasil a presença de cães infectados por Leishmania sp. tem sido freqüente em áreas endêmicas (Dias et al., 1977; Falqueto et al., 1986; Marzochi et al., 1988; Sessa et al., 1994). Na região Noroeste do Estado do Paraná, também foi constatada a presença de cães infectados (Lonardoni et al., 1993).

Nas áreas endêmicas onde a LT ocorre em crianças e adultos de ambos os sexos, com freqüência os cães estão infectados por Leishmania sp. (Coutinho et al., 1985; Falqueto et al., 1986) e os flebotomíneos são muito freqüentes no peridomicílio (Teodoro et al., 1993).

Com o objetivo de conhecer a epidemiologia da LT no Estado do Paraná, realizou-se inquérito sorológico em cães de seis propriedades agrícolas da Companhia Melhoramentos Norte do Paraná nos municípios de Jussara e Terra Boa, noroeste do Estado do Paraná.

\section{Material e Métodos}

\section{População canina}

Foram investigados 132 cães em seis propriedades agrícolas da Companhia Melhoramentos Norte do Paraná, nos anos de 1992 e 1993. Na Fazenda Palmital foram estudados 32 cães e 42 na Fazenda Mururê, ambas situadas no Município de Terra Boa. No município de Jussara foram investigados 12 cães na Cerâmica Andirá, 20 na Fazenda Jussara, 23 na Fazenda Lagoa e três nas Destilarias Melhoramentos. Estes animais foram examinados, procurandose verificar a existência de lesões, especialmente nas partes expostas do corpo como oreIhas, cauda, focinho e escroto. As informações sobre os cães constam de fichas com nome, raça e idade do cão, nome e endereço do proprietário.

\section{Soros}

De cada um dos cães, obteve-se amostra de sangue venoso. O soro sanguíneo foi separado, aliquotado e armazenado a -18ㅇ C até o uso.

Reação de imunofluorescência indireta para leishmaniose (IFI)

O antígeno foi preparado com Leishmania (Viannia) braziliensis conforme Silveira et al. (1990). A reação de IFI para leishmaniose foi realizada conforme Guimarães et al. (1974). Inicialmente realizou-se uma reação qualitativa com os soros diluídos a 1/20 em solução salina tamponada com fosfato (SST). Os soros que apresentaram-se positivos nesta reação foram então diluídos a partir de 1/20 em SST, em razão 2, para a determinação de seu título. Utilizou-se conjugado anti-imunoglobulina $\mathrm{G}$ de cão - isotiocianato de fluoresceína (Sigma) padronizado conforme Camargo (1973). Títulos iguais ou superiores a 40 foram considerados significativos (Marzochi et al., 1988).

Reação de Imunofluorescência Indireta para doença de Chagas

Utilizou-se antígeno de Trypanosoma cruzi (Biolab) e conjugado anti-imunoglobulina $\mathrm{G}$ de cão-isotiocianato de fluoresceína (Sigma) padronizado conforme Camargo (1973). A reação foi realizada conforme Camargo (1966), sendo os soros diluídos a partir de 1/ 20 em SST.

Pesquisa de Leishmania sp.

Dos cães que apresentavam lesão cutânea no momento da investigação, foi obtido material através de biópsia da borda da lesão. Este material foi utilizado para pesquisa de Leishmania sp. através de esfregaço por aposição em lâminas, as quais foram fixadas em metanol e coradas pelo método de Giemsa. Este mesmo material, conservado em solução salina fisiológica contendo $1.000 \mathrm{UI}$ de penicilina e $1 \mathrm{mg}$ de estreptomicina por $\mathrm{ml}$, foi triturado e inoculado nas patas posteriores de hamsters.

\section{Análise estatística}

A análise de proporções foi realizada utilizando-se o software "Microstat". 


\section{Resultados}

A Tabela 1 mostra a distribuição dos cães com títulos de anticorpos significativos na IFI para LT e dos cães com lesão, nas localidades estudadas. Dos 132 cães examinados, 24 (18,2\%) apresentaram títulos de anticorpos anti-Leishmania iguais ou superiores a 40 através da técnica de IFI. Foram observadas lesões em quatro (16,7\%) dos cães com IFI positiva e em dois (1,9\%) dos cães com IFI negativa. Estes seis cães com lesões foram submetidos à biópsia e todos foram negativos para Leishmania sp. ao exame microscópico direto e os hamsters inoculados com os materiais das biópsias não desenvolveram LT. O percentual de cães, na Fazenda Jussara, com títulos de anticorpos significativos na IFI para leishmaniose foi superior ao encontrado na Fazenda Mururê $(p<$ $0,01)$ mas não foi estatisticamente diferente dos percentuais encontrados nas outras localidades $(p>0,05)$.

Na Tabela 2 são encontrados os resultados das reações de IFI para LT e Doença de Chagas dos cães que apresentaram títulos de anticorpos 40 na IFI para LT. Pode-se observar que todos os 24 cães tiveram títulos de anticorpos para T. cruzi inferiores aos títulos de anticorpos para Leishmania sp.

\section{Discussão}

A leishmaniose tegumentar constitui um problema de saúde no Brasil (Guimarães et al., 1983; Grimaldi et al., 1989), inclusive no Estado do Paraná (Verzignassi et al., 1988; Teodoro et al., 1991; Silveira et al., 1992; Silveira et al., 1994). A presença de cães infectados em áreas endêmicas de leishmaniose tegumentar tem sido investigada, considerando seu papel como reservatório na cadeia de transmissão de Leishmania sp. nos ambientes domiciliar e peridomiciliar (Falqueto et al., 1986; 1991; Barreto et al., 1984; Coutinho et al., 1985; Sessa et al.,1994). Na região Noroeste do Estado do Paraná, Lonardoni et al. (1993) registraram a presença de cães infectados por Leishmania (Viannia) braziliensis.

A pesquisa de anticorpos em cães de área endêmica de leishmaniose tegumentar vem sendo realizada com o uso da técnica de IFI, e títulos significativos de anticorpos têm sido demonstrados em cães portadores ou não de lesões. Percentuais de cães com sorologia positiva, semelhantes aos encontrados neste trabaIho (18,2\%), foram relatados por Marzochi et al. (1988) em uma zona endêmica no Rio de Janei-
Tabela 1

Distribuição dos cães com títulos significativos de anticorpos na reação de Imunofluorescência Indireta para leishmaniose tegumentar e número de cães com lesão, dos 132 cães estudados em seis localidades da região Noroeste do Estado do Paraná, em 1992 e 1993.

\begin{tabular}{lcccc}
\hline \multicolumn{1}{c}{ Localidade } & examinados & $\begin{array}{c}\text { no de cães } \\
\text { com IFI positiva }\end{array}$ & $\%$ & com lesão \\
\hline 1) Fazenda Palmital & 32 & 4 & 12,5 & 5 \\
2) Cerâmica Andirá & 12 & 2 & 16,6 & 1 \\
3) Fazenda J ussara & 20 & 8 & 40,0 & - \\
4) Fazenda Lagoa & 23 & 6 & 26,1 & - \\
5) Destilaria Melhoramentos & 3 & 1 & 33,3 & - \\
6) Fazenda Mururê & 42 & 3 & 7,1 & - \\
Total & 132 & 24 & 18,2 & 6 \\
\hline
\end{tabular}

*Análise de Proporções:

1 e 2) $Z=-0,359 ; p=0,3599$

1 e 3) $Z=-2,290 ; p=0,0110$

1 e 4) $Z=-1,289 ; p=0,0988$

1 e 5$) Z=-0,986 ; p=0,1621$
2 e 3) $Z=-1,379 ; p=0,0840$

2 e 4) $Z=-0,630 ; p=0,2644$

2 e 5) $Z=-0,645 ; p=0,2593$

2 e 6) $Z=1,004 ; p=0,1577$

3 e 4) $Z=0,971 ; p=0,1657$

3 e 6) $Z=3,166 ; p=7,733 \times 10-4$

4 e 5) $Z=-0,266 ; p=0,3951$

5 e 6$) Z=1,540 ; p=0,0618$
3 e 5) $Z=0,221 ; p=0,4127$

4 e 6) $Z=2,114 ; p=0,0172$

Tabela 2

Resultados das reações de imunofluorescência

indireta (IFI) para leishmaniose tegumentar e Doença de Chagas, dos cães que apresentaram títulos 40 na imunofluorescência para leishmaniose tegumentar.

\begin{tabular}{|c|c|c|}
\hline \multirow{2}{*}{$\begin{array}{c}\text { Cão } \\
\text { no }\end{array}$} & \multicolumn{2}{|c|}{ Título de Anticorpos na IFI } \\
\hline & Leishmaniose & Doença de Chagas \\
\hline 33 & 40 & 20 \\
\hline 36 & 320 & 20 \\
\hline 37 & 320 & 80 \\
\hline 38 & 320 & 80 \\
\hline 44 & 80 & 20 \\
\hline 46 & 160 & 20 \\
\hline 56 & 80 & 20 \\
\hline 58 & 160 & 20 \\
\hline 63 & 80 & 20 \\
\hline 64 & 80 & 20 \\
\hline 66 & 80 & 20 \\
\hline 67 & 160 & 20 \\
\hline 69 & 160 & 40 \\
\hline 70 & 160 & 40 \\
\hline 76 & 320 & 40 \\
\hline 79 & 40 & 20 \\
\hline 84 & 40 & 20 \\
\hline 87 & 80 & 20 \\
\hline 90 & 80 & 20 \\
\hline 92 & 80 & 20 \\
\hline 96 & 40 & 20 \\
\hline 98 & 80 & 20 \\
\hline 113 & 40 & 20 \\
\hline 128 & 80 & 20 \\
\hline
\end{tabular}


ro, onde $22,9 \%$ (11/48) dos cães tinham títulos de anticorpos maiores ou iguais a 40 , sendo que dos 11 somente nove apresentavam lesões ulceradas. Pirmez et al. (1988) detectaram títulos de anticorpos através da IFI em 32 dentre 35 cães com suspeita de leishmaniose tegumentar, em Jacarepaguá - RJ, sendo demonstrada a presença de Leishmania sp. em 32 deles.

Falqueto et al. (1986) estudaram 186 cães de uma região endêmica do Espírito Santo, sendo que 46 deles apresentavam lesões suspeitas e 31 estavam parasitados por leishmânias. Dias et al. (1977) investigaram 355 cães em área endêmica de Minas Gerais e encontraram 27 com lesões ou manchas hipocrômicas, 11 dos quais foram encontrados parasitados, sendo que em apenas seis o esfregaço por aposição foi positivo. Para estes últimos autores, o esfregaço por aposição não constitui processo ideal para diagnóstico de leishmaniose tegumentar, devido ao baixo número de parasitas presentes nas lesões, tornando-se necessário o exame de várias preparações para a detecção de formas amastigotas nas lesões dos cães, o que talvez justifique os resultados negativos neste trabalho, pois de cada cão foram confec-

\section{Agradecimentos}

À Companhia Melhoramentos Norte do Paraná pelo auxílio imprescindível à realização deste trabalho. À Dra Marta de Lana da Universidade Federal de Ouro Preto pela doação de soro de cão chagásico. Aos técnicos de laboratório Luiz Saraiva Arraes, João Balduíno Kuhl, Sandra Vieira da Silva e Dilma Figueiredo Botter, pelo apoio técnico. cionadas apenas três lâminas para exame microscópico direto.

Os ambientes domiciliares e peridomiciliares na Fazenda Jussara são mais favoráveis à ocorrência do ciclo de transmissão de Leishmania sp. pela presença de cães com títulos significativos de anticorpos e de cães infectados (Lonardoni et al., 1993); além disso, tem sido grande o número de flebotomíneos capturados nesta fazenda (Teodoro et al., 1994).

\section{Conclusão}

O elevado número de cães com sorologia positiva para leishmaniose tegumentar explica, em parte, a alta endemicidade da doença na região Noroeste do Estado do Paraná. Nossos resultados mostram que o cão pode ser um importante reservatório doméstico de Leishmania sp. à semelhança do que acontece em outras áreas endêmicas do Brasil. No entanto, há necessidade de se ampliar a área de abrangência deste tipo de estudo para melhor conhecimento da epidemiologia da leishmaniose tegumentar no Estado do Paraná.

\section{Referências}

BARROS, G. C.; SESSA, P. A.; MATTOS, E. A.; CARIAS, V. R. D.; MAYRINK, W.; ALENCAR, J. T. A.; FALQUETO, A. \&JESUS, A. C., 1985. Foco de leishmaniose tegumentar americana nos municípios de Viana e Cariacica, Estado do Espírito Santo, Brasil. Revista de Saúde Pública, 19:146-153.

BARRETO, A. C.; CUBA, C. A. C.; VEXENAT, J. A.; ROSA, A. C.; MARSDEN, P. D. \& MAGALHÃES, A. V., 1984. Características epidemiológicas da leishmaniose tegumentar americana em uma região endêmica do Estado da Bahia. II - Leishmaniose canina. Revista da Soci edade Brasileira de Medicina Tropical, 17:59-65.

CAMARGO, M. E., 1966. Fluorescent antibody test for the serodiagnosis of american trypanosomiasis. Technical modification employing culture forms of Trypanosoma cruzi in a slide test. Revista do Instituto de Medicina tropical deSão Paulo, 8:227-234. 
CAMARGO, M. E., 1973. Introdução às Técnicas de Imunofluorescência. São Paulo: Instituto de Medicina Tropical de São Paulo.

COUTINHO, S. G.; MARZOCHI, M. C. A.; SOUZA, W. J. S. \& AMENDOEIRA, M. R. R., 1981. Leishmaniose tegumentar americana. Jornal Brasileiro de Medicina, 41:104-118

COUTINHO, S. G.; NUNES, M. P.; MARZOCHI, M. C. A. \& TRAM ONTANO, N., 1985. A survey for american cutaneous and visceral leishmaniasis among 1342 dogs from areas in Rio de Janeiro (Brazil) where the human diseases occur. Memórias do Instituto Oswaldo Cruz, 80:17-22.

DIAS, M.; MAYRINK, W.; DEANE, L. M.; DA COSTA, C. A.; MAGALHÃES, P. A.; MELO, M. N.; BATISTA, S. M.; ARAÚJO, F. G.; COELHO, M. V. \& WILLIAMS, P., 1977. Epidemiologia da leishmaniose tegumentar americana. I - Estudo de reservatórios em área endêmica no Estado de Minas Gerais. Revista do Institulo Medicina Tropical de São Paulo, 19:403-410.

FALQUETO, A.; COURA, J. R.; BARROS, G. C.; GRIMALDI Fo, G.; SESSA, P. A.; CARIAS, V. R. D.; JESUS, A. C. \& ALENCAR, J. T. A., 1986. Participação do cão no ciclo de transmissão da leishmaniose tegumentar no município de Viana, Estado do Espírito Santo, Brasil. Memórias do Instituto Oswaldo Cruz, 81:155-163.

FALQUETO, A.; SESSA, P. A.; VAREJÃO, J. B.; BARROS, G. C.; MOMEN, H. \& GRIMALDI Jr., G., 1991. Leishmaniasis due to Leishmania braziliensis in Espírito Santo state, Brazil. Further evidence on the role of dogs as a reservoir of infection for humans. Memórias do Instituto Oswal do Cruz, 86:499-500.

FNS (Fundação Nacional de Saúde), 1993. Guia de Controle da Lei shmaniose Tegumentar Americana. Brasília: Ministério da Saúde.

GRIMALDI JR., G.; TESH, R. B. \& MCMAHON-PRATT, D., 1989. A review of the geografic distribution and epidemiology of leishmaniasis in the new world. American Journal of Tropical Medicineand Hygiene, 41:687-725.

GUIMARÃES, M. C. S.; GIOVANNINI, V. L. \& CAMARGO, M. E., 1974. Antigenic standardization from mucocutaneous leishmaniasis immunofluorescence test. Revista do Instituto de Medicina Tropical de São Paulo, 16:145-148.

GUIMARÃES, M. C. S.; CELESTE, B. J.; CAM ARGO, M. E. \& DINIZ, J. M. P., 1983. Seroepidemiology of cutaneous leishmaniasis from Ribeira do I guape Valley. IgM and IgG antibodies detected by means of an immunoenzymatic assay (ELISA). Revista do Instituto de Medicina Tropical de São Paulo, 25:108-112.

LONARDONI, M. V. C.; TEODORO, U.; ARRAES, S. M. A. A.; SILVEIRA, T. G. V.; BERTOLINI, D. A.; ISHIKAWA, E. A. Y. \& SHAW, J. J., 1993. Nota sobre leishmaniose canina no noroeste do Estado do Paraná, sul do Brasil. Revista de Saúde Pública, 27:378-379.

MARZOCHI, M. C. A. \& BARBOSA-SANTOS, E. G. O., 1988. Evaluation of a skin test on the canine mucocutaneous leishmaniasis diagnosis. Memórias do Instituto Oswal do Cruz, 83:391-392.

PIRMEZ, C.; COUTINHO, S. G.; MARZOCHI, M. C. A.; NUNES, M. P. \& GRIMALDI JR., G., 1988. Canine american cutaneous leishmaniasis: a clinical and immunological study in dogs naturally infected with Leishmania braziliensis in an endemic area of Rio de Janeiro, Brazil. American Journal of Tropical Medicine and Hygiene, 38:52-58.

SESSA, P. A.; FALQUETO, A. \&VAREJÃO, J. B. M., 1994. Tentativa de controle da leishmaniose tegumentar americana por meio do tratamento dos cães doentes. Cadernos de Saúde Pública, 10:457-463.

SI LVEIRA, T. G. V.; ARRAES, S. M. A. A.; PEREIRA, D. S.; LONARDONI, M. V. C.; DIAS, M. L. G. G.; RAMOS, M.; BERTOLINI, D. A.; FRESSATTI, R. \& MISUTA, N. M., 1990. Avaliação da reação de imunofluorescência indireta para leishmaniose tegumentar americana em pacientes da região noroeste do Estado do Paraná - Brasil. Revista Unimar 12:177-188.

SILVEIRA, T. G. V.; LONARDONI, M. V. C.; ARRAES, S. M. A. A.; BERTOLINI, D. A.; RAMOS, M. \&TEODORO, U., 1992. Leishmaniose tegumentar americana - aspectos epidemiológicos no norte do Estado do Paraná - Brasil. In: IV Encontro Científico da Universidade Estadual de Maringá, Resumos. Maringá, Paraná, Brasil.

SILVEIRA, T. G. V.; TEODORO, U.; LONARDONI, M. V. C.; GUILHERME, A. L. F.; TOLEDO, M. J. O.; RAMOS, M.; ARRAES, S. M. A. A.; BERTOLINI, D. A.; SPINOSA, R. P. \& BARBOSA, O. C., 1994. Investigação epidemiológica da leishmaniose tegumentar em área endêmica no Estado do Paraná, sul do Brasil. Memórias do Instituto Oswaldo Cruz, 89:181.

TEODORO, U.; SPINOSA, R. P.; LA SALVIA FILHO, V.; GUILHERME, A.L. F.; LIMA, A. P.; JUNQUEIRA, G. M. B.; MISUTA, N. M. NERILO SOBRINHO, A, \& LIMA, E. M., 1991. Da necessidade de se adotar e divulgar esquemas terapêuticos para tratamento de leishmaniose tegumentar no Paraná. Revista do Instituto de Medicina Tropical de São Paulo, 33:199-204.

TEODORO, U.; LA SALVIA FILHO, V.; LIMA, E. M.; SPINOSA, R. P.; BARBOSA, O. C.; FERREIRA, M. E. M. C. \& LONARDONI, M. V. C., 1993. Observações sobre o comportamento de flebotomíneos em ecótopos florestais e extraflorestais, em área endêmica de leishmaniose tegumentar americana, no norte do Estado do Paraná, sul do Brasil. Re vista de Saúde Pública, 27:242-249.

TEODORO, U.; KUHL, J. B.; BARBOSA, O. C.; SOCCOL, V. T.; LOZOVEI, A. L. SILVEIRA, T. G. V. \& ROBERTO, A. C. B. S., 1994. O saneamento ambiental e a organização peridomiciliar como medidas auxiliares no controle de flebotomíneos, no Estado do Paraná, sul do Brasil. Memórias do Instituto Oswaldo Cruz, 89:206.

VERZIGNASSI, T. G.; PEREIRA, D. S.; TEODORO, U .; MISUTA, N. M; DIAS, M. L. G. G.; FERREIRA, M. E. M. C.; FRESSATTI, R. \& ARISTIDES, S. M. A., 1988. Leishmaniose tegumentar americana: aspectos epidemiológicos no norte do Paraná Brasil. Ciência e Cultura, 40:884.

VIEIRA, J. B.; LACERDA, M. M. \& MARSDEN, P. D., 1990. National reporting of leishmaniasis: the brazilian experience. Parasitology Today, 6:339340. 